\title{
KARAKTERISTIK MATRIKS SOFT
}

\author{
Saman Abdurrahman \\ Thresye \\ FMIPA, Universitas Lambung Mangkurat \\ e-mail: saman@ulm.ac.id
}

\begin{abstract}
A soft set is a concept of the set that plays an essential role in overcoming vagueness. The soft set is an extension of the fuzzy set concept. One of the products of the soft set is a soft matrix. A soft matrix is a matrix formed into a soft set's membership value whose entries are elements at $\{0,1\}$. This paper aims to introduce operations on soft matrices, i.e., intersection, union, and complements. Further, algebraic properties of soft matrix operations were investigated, commutative, associative, distributive laws, De Morgan's laws, and absorption.
\end{abstract}

Keywords: soft matrix, union, intersection and complement

\begin{abstract}
ABSTRAK
Himpunan soft merupakan suatu konsep himpunan yang berperan penting dalam mengatasi ketidakpastian. Himpunan soft merupakan perluasan dari konsep himpunan fuzzy. Salah satu produk dari himpunan soft adalah matriks soft. Matriks soft adalah matriks yang dibentuk dari nilai keanggotaan himpunan soft yang entri-entrinya elemen di $\{0,1\}$. Paper ini, bertujuan memperkenalkan operasi-operasi pada matriks soft, yaitu irisan, gabungan, dan komplemen. Lebih lanjut, diselidiki sifat-sifat aljabar operasi matriks soft, yaitu komutatif, asosiatif, hukum distributive, hukum De Morgan's, dan absorpsi.
\end{abstract}

Kata kunci: matriks soft, gabungan, irisan dan konplemen 
Konsep himpunan fuzzy, pertama kali diperkenalkan oleh Zadeh pada tahun 1965. Sejak itu, banyak peneliti tertarik untuk melanjutkan penelitian himpunan fuzzy, terutama mengaplikasikan pada disiplin ilmu lain. Salah satunya pada bidang aljabar, dimotori oleh Rosenfeld (1971), yang melahirkan konsep grup fuzzy. Penelitian Rosenfeld ini, memberikan warna baru pada penelitian bidang aljabar, dikarenakan konsep grup fuzzy oleh peneliti berikutnya, dijadikan dasar untuk membangun definsi ataupun sifat baru pada struktur aljabar yang lain. Salah satunya, Abdurrahman (2020) mengaplikasikannya pada struktur semiring.

Seiring dengan perkembangan zaman, ilmu pengetahuan dan teknologi semakin berkembang pesat, beberapa peneliti melakukan inovasi ataupun koreksi pada penelitian sebelumnya demi menghasilkan suatu konsep baru, diantaranya Molodtsov (1999) melakukan koreksi pada konsep himpunan fuzzy.

Molodtsov menemukan kelemahan dan kesulitan pada himpunan fuzzy. la menilai, teori himpunan fuzzy hanya bisa menyelesaikan permasalahan dengan satu parameter saja, sehingga perlu ditambahkan kondisi lain, agar bisa menutupi kelemahan tersebut. Dari kondisi ini, Molodtsov memperkenalkan teori baru yang terbebas dari kelemahan dan kesulitan yang ditemukannya pada himpunan fuzzy, teori ini disebut dengan teori himpunan soft.

Salah satu konsep yang dapat diturunkan dari konsep himpunan soft adalah matriks soft. Konsep matriks soft, berbeda dengan konsep matriks biasa, yang dikenal ada aljabar linear elementer. Dari bentuk matriksnya, matriks soft sama dengan matriks biasa. Tetapi, la berbeda dari pendefinisian operasinya. Operasi yang dibagun pada matriks soft, diantaranya: operasi gabungan $\widetilde{U}$, operasi irisan $\widetilde{\cap}$ dan operasi konplemen. Operasi-operasi yang dimiliki oleh matriks soft, sama dengan operasi himpunan dari segi penamaannya.

Berdasarkan fakta di atas, muncul suatu permasalahan, yaitu: Apakah dari nama yang sama pada operasi dan berbeda pada pendefinisian operasinya, mempunyai sifat yang analog? Dengan kata lain apakah sifat-sifat yang dimiliki himpunan, yaitu: Sifat involusi, sifat idempoten, sifat identitas, sifat konplemen, sifat komutatif, sifat asosiatif, sifat De Morgan's, sifat distributif dan sifat absorpsi (penyerapan), dimiliki oleh matriks soft? Pertanyaan inilah, yang menjadikan motivasi penelitian ini dilakukan.

Berdasarkan pertanyaan tersebut di atas, pada artikel ini akan diselidiki sifat involusi, sifat idempoten, sifat identitas, sifat konplemen, sifat komutatif, sifat asosiatif, sifat De Morgan's, sifat distributif dan sifat absorpsi (penyerapan) pada matriks soft, dengan cara menginduksi sifat-sifat pada himpunan.

\section{METODE}

Penelitian yang dilaksanakan adalah kajian teori, yang merujuk pada buku ataupun jurnal yang berhubungan dengan teori himpunan, himpunan soft dan matriks soft. Berikut ini, diberikan definisi yang mendukung pada bagian pembahasan.

Untuk memudahkan dalam penyebutan notasi dan tidak terjadi pengulangan pada notasi tersebut, berikut diberikan beberapa notasi, yaitu $\mathbb{U}$ menyatakan himpunan semesta, $P(\mathbb{U})$ menyatakan koleksi subhimpunan dari $\mathbb{U}$, dan $\mathbb{A}$ dan $\mathbb{E}$ adalah himpunan parameter dengan $\mathbb{A} \subseteq \mathbb{E}$.

Definisi 2.1. (Maji et al., 2003; Molodtsov, 1999) Suatu pasangan $\left(\mathbb{f}_{\mathbb{A}}, \mathbb{E}\right)$ disebut himpunan soft atas $\mathbb{U}$ jika dan hanya jika $\mathbb{f}_{\mathbb{A}}$ adalah suatu pemetaan dari $\mathbb{E}$ ke koleksi subhimpunan dari $\mathbb{U}$, dengan kata lain,

$$
\mathbb{f}_{\mathbb{A}}: \mathbb{E} \rightarrow \mathrm{P}(\mathbb{U})
$$


sedemikian sehingga $\mathbb{f}_{\mathbb{A}}(e)=\emptyset j i k a ~ e \notin \mathbb{E}$.

Dalam hal ini, $\mathbb{f}_{\mathbb{A}}$ disebut approksimasi fungsi dari himpunan soft $\left(\mathbb{f}_{\mathbb{A}}, \mathbb{E}\right)$. Untuk setiap $x \in \mathbb{E}$, himpunan $\mathbb{f}_{\mathbb{A}}(x)$ disebut $x$ - aproksimasi elemen dari himpunan soft $\left(\mathbb{f}_{\mathbb{A}}, \mathbb{E}\right)$ yang berkaitan dengan parameter $\mathrm{x} \in \mathbb{E}$. Selain itu, himpunan soft $\left(\mathbb{f}_{\mathbb{A}}, \mathbb{E}\right)$ atas $\mathbb{U}$ dapat dinotasikan sebagai:

$$
\left(\mathbb{f}_{\mathbb{A}}, \mathbb{E}\right)=\left\{\left(x, \mathbb{f}_{\mathbb{A}}(x)\right) \mid x \in \mathbb{E}, \mathbb{f}_{\mathbb{A}}(x) \in P(\mathbb{U})\right\} .
$$

Elemen-elemen dari himpunan soft yang memiliki aproksimasi elemen kosong, biasanya tidak dituliskan. Dalam himpunan soft dengan menggunakan himpunan parameter tunggal, penulisan $\mathbb{E}$ dalam himpunan soft $\left(\mathbb{f}_{\mathbb{A}}, \mathbb{E}\right)$ bisa dihilangkan, sehingga himpunan soft $\left(\mathbb{F}_{\mathbb{A}}, \mathbb{E}\right)$ dapat ditulis sebagai himpunan soft $\mathbb{f}_{\mathbb{A}}$. Selain itu, koleksi dari semua himpunan soft dengan menggunakan himpunan parameter tunggal dinotasikan dengan $\mathbb{S}$.

Contoh 2.1. Diberikan suatu himpunan soft $\left(\mathbb{f}_{\mathbb{A}}, \mathbb{E}\right)$ yang mendeskripsikan tentang "daya tarik rumah", yang menjadi pertimbangan untuk dibeli. Misalkan terdapat 6 rumah dalam semesta

$$
\mathbb{U}=\left\{h_{1}, h_{2}, h_{3}, h_{4}, h_{5}, h_{6}\right\},
$$

yang dipertimbangkan dan himpunan parameter

$$
\mathbb{A}=\left\{a_{1}, a_{2}, a_{3}, a_{4}, a_{5}\right\}
$$

sebagai himpunan parameter penentu, dengan $a_{1}=$ mahal, $a_{2}=$ indah, $a_{3}=$ dari kayu, $a_{4}=$ murah dan $a_{5}=$ dikelilingi pemandangan hijau. Fungsi $\mathbb{f}_{\mathbb{A}}$ diberikan oleh "rumah $(\cdot)$ " dengan $(\cdot)$ akan diisi satu dari parameter $a \in \mathbb{A}$. Bentuk $\mathbb{f}_{\mathbb{A}}\left(a_{1}\right)$ bermakna "rumah (mahal)" dan nilai fungsinya adalah

$\{h \in \mathbb{U} \mid$ adalah rumah mahal $\}$

Misalkan, $\mathbb{f}_{\mathbb{A}}\left(a_{1}\right)=\left\{h_{2}, h_{4}\right\}, \mathbb{f}_{\mathbb{A}}\left(a_{2}\right)=\left\{h_{1}, h_{3}\right\}, \mathbb{f}_{\mathbb{A}}\left(a_{3}\right)=\emptyset, \mathbb{f}_{\mathbb{A}}\left(a_{4}\right)=\left\{h_{1}, h_{3}, h_{5}\right\}$, dan $\mathbb{f}_{\mathbb{A}}\left(a_{5}\right)=\left\{h_{1}\right\}$, dapat dituliskan himpunan soft $\left(\mathbb{F}_{\mathbb{A}}, \mathbb{E}\right)$, terdiri atas koleksi deskripsi aproksimasi dari calon rumah, yaitu:

$$
\begin{aligned}
\left(\mathbb{F}_{\mathbb{A}}, \mathbb{E}\right)=\{ & \left(\text { rumah mahal, }\left\{h_{2}, h_{4}\right\}\right),\left(\text { rumah indah, }\left\{h_{1}, h_{3}\right\}\right), \\
& \text { (rumah dari kayu, } \varnothing),\left(\text { rumah murah, }\left\{h_{1}, h_{3}, h_{5}\right\}\right), \\
& \text { (dikelilingi pemandangan hijau, } \left.\left.\left\{h_{1}\right\}\right)\right\} .
\end{aligned}
$$

Setiap deskripsi aproksimasi mempunyai dua bagian, yaitu: predikat dan himpunan nilai aproksimasi. Jadi, aproksimasi "rumah mahal $=\left\{h_{2}, h_{4}\right\}$ " mempunyai predikat "rumah mahal" dan himpunan nilai aproksimasinya " $\left\{h_{2}, h_{4}\right\}$ ".

Definisi 2.2. (Çağman \& Enginoğlu, 2010; Mondal \& Pal, 2011; Vijayabalaji \& Ramesh, 2013; Zhang, 2014) Misalkan $\left(\mathbb{F}_{\mathbb{A}}, \mathbb{E}\right)$ adalah himpunan soft atas $\mathbb{U}$.

i) Subset dari $\mathbb{U} \times \mathbb{E}$ dapat didefinisikan oleh

$$
\mathcal{R}_{\mathbb{A}}=\left\{(\mathrm{u}, \mathrm{e}) \mid \mathrm{e} \in \mathbb{A}, \mathrm{u} \in \mathbb{f}_{\mathbb{A}}(\mathrm{e})\right\},
$$

yang disebut bentuk relasi dari $\left(\mathbb{f}_{\mathbb{A}}, \mathbb{E}\right)$.

ii) Fungsi karakteristik $\mathcal{R}_{\mathbb{A}}$ dinyatakan oleh:

$$
\chi_{\mathcal{R}_{\mathbb{A}}}: \mathbb{U} \times \mathbb{E} \rightarrow\{0,1\}, \text { dengan } \chi_{\mathcal{R}_{\mathbb{A}}}(\mathrm{u}, \mathrm{e})= \begin{cases}1, & (u, e) \in \mathcal{R}_{\mathbb{A}} \\ 0, & (u, e) \notin \mathcal{R}_{\mathbb{A}}\end{cases}
$$


iii) Jika $\mathbb{U}=\left\{u_{1}, u_{2}, \ldots, u_{m}\right\}, \mathbb{E}=\left\{e_{1}, e_{2}, \ldots, e_{n}\right\}$ dan $\mathbb{A} \subseteq \mathbb{E}$, maka $\mathcal{R}_{\mathbb{A}}$ dapat disajikan dalam bentuk tabel berikut:

\begin{tabular}{c|cccc}
$\mathcal{R}_{\mathbb{A}}$ & $e_{1}$ & $e_{2}$ & $\cdots$ & $e_{n}$ \\
\hline $\mathrm{u}_{1}$ & $\chi_{\mathcal{R}_{\mathbb{A}}}\left(\mathrm{u}_{1}, \mathrm{e}_{1}\right)$ & $\chi_{\mathcal{R}_{\mathbb{A}}}\left(\mathrm{u}_{1}, \mathrm{e}_{2}\right)$ & $\cdots$ & $\chi_{\mathcal{R}_{\mathbb{A}}}\left(\mathrm{u}_{1}, \mathrm{e}_{\mathrm{n}}\right)$ \\
$\mathrm{u}_{2}$ & $\chi_{\mathcal{R}_{\mathbb{A}}}\left(\mathrm{u}_{2}, \mathrm{e}_{1}\right)$ & $\chi_{\mathcal{R}_{\mathbb{A}}}\left(\mathrm{u}_{2}, e_{2}\right)$ & $\cdots$ & $\chi_{\mathcal{R}_{\mathbb{A}}}\left(\mathrm{u}_{2}, \mathrm{e}_{\mathrm{n}}\right)$ \\
$\vdots$ & $\vdots$ & $\vdots$ & $\ddots$ & $\vdots$ \\
$\mathrm{u}_{\mathrm{m}}$ & $\chi_{\mathcal{R}_{\mathbb{A}}}\left(\mathrm{u}_{\mathrm{m}}, \mathrm{e}_{1}\right)$ & $\chi_{\mathcal{R}_{\mathbb{A}}}\left(\mathrm{u}_{\mathrm{m}}, e_{2}\right)$ & $\cdots$ & $\chi_{\mathcal{R}_{\mathbb{A}}}\left(\mathrm{u}_{\mathrm{m}}, \mathrm{e}_{\mathrm{n}}\right)$
\end{tabular}

iv) Jika $a_{i j}=\chi_{\mathcal{R}_{\mathbb{A}}}\left(\mathrm{u}_{\mathrm{i}}, \mathrm{e}_{\mathrm{j}}\right)$, maka didefinisikan suatu matriks

$$
\left[a_{i j}\right]_{m \times n} \stackrel{\text { def }}{=}\left(\begin{array}{cccc}
a_{11} & a_{11} & \cdots & a_{1 n} \\
a_{21} & a_{22} & \cdots & a_{2 n} \\
\vdots & \vdots & \ddots & \vdots \\
a_{m 1} & a_{m 2} & \cdots & a_{m n}
\end{array}\right),
$$

yang disebut matriks soft berordo $m \times n$ dari himpunan soft $\left(\mathbb{f}_{\mathbb{A}}, \mathbb{E}\right)$ atas $\mathbb{U}$.

Menurut Definisi 2.2, himpunan soft $\left(\mathbb{f}_{\mathbb{A}}, \mathbb{E}\right)$ merupakan karakteristik dari matriks $\left[a_{i j}\right]_{m \times n}$. Ini berarti, himpunan soft $\left(\mathbb{f}_{\mathbb{A}}, \mathbb{E}\right)$ secara formal sama dengan matriks soft $\left[a_{i j}\right]_{m \times n}$. Oleh karena itu, kita akan mengidentifikasi himpunan soft dengan matriks soft dan mengunakan dua konsep ini, yang dapat saling menggantikan.

Koleksi dari matriks soft berordo $m \times n$ atas $\mathbb{U}$ dinotasikan dengan $\mathbb{M}_{\mathbb{S}_{m \times n}}$. Selanjutnya, penulisan $\left[a_{i j}\right]_{m \times n}$ dinyatakan dengan $\left[a_{i j}\right]$. Kondisi $\left[a_{i j}\right] \in \mathbb{M}_{\mathbb{S}_{m \times n}}$, menyatakan bahwa $\left[a_{i j}\right]$ suatu matriks soft berordo $m \times n$ dengan $i=1,2, \ldots, m$ dan $j=1,2, \ldots, n$.

Contoh 2.2. Misalkan $\mathbb{U}=\left\{u_{1}, u_{2}, u_{3}, u_{4}, u_{5}\right\}$ adalah himpunan semesta dan

$$
\begin{aligned}
& \mathbb{E}=\left\{e_{1}, e_{2}, e_{3}, e_{4}\right\} \text { adalah himpunan parameter. Jika } \mathbb{A}=\left\{e_{2}, e_{3}, e_{4}\right\} \text { dan } \\
& \mathbb{f}_{\mathbb{A}}\left(e_{2}\right)=\left\{u_{2}, u_{4}\right\}, \mathbb{f}_{\mathbb{A}}\left(e_{3}\right)=\emptyset, \mathbb{f}_{\mathbb{A}}\left(e_{4}\right)=\mathbb{U}, \text { maka himpunan soft } \\
& \left(\mathbb{f}_{\mathbb{A}}, \mathbb{E}\right)=\left\{\left(e_{2},\left\{u_{2}, u_{4}\right\}\right),\left(e_{4}, \mathbb{U}\right)\right\}, \text { dan relasi dari }\left(\mathbb{f}_{\mathbb{A}}, \mathbb{E}\right) \text { adalah } \\
& \mathcal{R}_{\mathbb{A}}=\left\{\left(u_{2}, e_{2}\right),\left(u_{4}, e_{4}\right),\left(u_{1}, e_{4}\right),\left(u_{2}, e_{4}\right),\left(u_{3}, e_{4}\right),\left(u_{4}, e_{4}\right),\left(u_{5}, e_{4}\right)\right\} .
\end{aligned}
$$

Oleh karena itu, matriks soft

$$
\left[a_{i j}\right]=\left(\begin{array}{llll}
0 & 0 & 0 & 1 \\
0 & 1 & 0 & 1 \\
0 & 0 & 0 & 1 \\
0 & 1 & 0 & 1 \\
0 & 0 & 0 & 1
\end{array}\right)
$$


Berikut disajikan jenis-jenis matriks soft, berdasarkan entri-entri penyusun matriks softnya.

Definisi 2.3. (Çağman \& Enginoğlu, 2010) Jika $\left[a_{i j}\right] \in \mathbb{M}_{\mathbb{S}_{m \times n}}$, maka $\left[a_{i j}\right]$ disebut:

i) Matriks soft nol, dinotasikan dengan [0], jika $a_{i j}=0$ untuk setiap $i$ dan $j$.

ii) Matriks soft $\mathbb{A}$-semesta, dinotasikan dengan $\left[\tilde{a}_{i j}\right]$, jika $a_{i j}=1$ untuk setiap $j \in I_{\mathbb{A}}=$ $\left\{j \mid e_{j} \in \mathbb{A}\right\}$ dan $i$.

iii) Matriks soft semesta, dinotasikan dengan [1], jika $a_{i j}=1$ untuk setiap $i$ dan $j$.

Contoh 2.3. Misalkan $\mathbb{U}=\left\{u_{1}, u_{2}, u_{3}, u_{4}, u_{5}\right\}$ adalah himpunan semesta, $\mathbb{E}=\left\{e_{1}, e_{2}, e_{3}, e_{4}\right\}$ adalah himpunan parameter dan $\left[a_{i j}\right],\left[b_{i j}\right],\left[c_{i j}\right] \in \mathbb{M}_{\mathbb{S}_{5 \times 4}}$.

Jika $\mathbb{A}=\left\{e_{2}, e_{4}\right\}$ dan $\mathbb{f}_{\mathbb{A}}\left(e_{2}\right)=\emptyset, \mathbb{f}_{\mathbb{A}}\left(e_{4}\right)=\emptyset$, maka $\left[a_{i j}\right]=[0]$ adalah matriks soft nol, yaitu:

$$
[0]=\left(\begin{array}{llll}
0 & 0 & 0 & 0 \\
0 & 0 & 0 & 0 \\
0 & 0 & 0 & 0 \\
0 & 0 & 0 & 0 \\
0 & 0 & 0 & 0
\end{array}\right) .
$$

Jika $\mathbb{B}=\left\{e_{1}, e_{4}\right\}$ dan $\mathbb{f}_{\mathbb{B}}\left(e_{1}\right)=\mathbb{U}, \mathbb{f}_{\mathbb{B}}\left(e_{4}\right)=\mathbb{U}$, maka $\left[b_{i j}\right]=\left[\tilde{b}_{i j}\right]$ adalah matriks soft $\mathbb{B}$-semesta, yaitu:

$$
\left[\tilde{b}_{i j}\right]=\left(\begin{array}{cccc}
1 & 0 & 0 & 1 \\
1 & 0 & 0 & 1 \\
1 & 0 & 0 & 1 \\
1 & 0 & 0 & 1 \\
1 & 0 & 0 & 1
\end{array}\right)
$$

Jika $\mathbb{C}=\mathbb{E}$ dan $\mathbb{f}_{\mathbb{C}}\left(e_{i}\right)=\mathbb{U}$ untuk setiap $e_{i} \in \mathbb{C}, i=1,2,3,4$, maka $\left[c_{i j}\right]=[1]$ adalah matriks soft semesta, yaitu:

$$
[1]=\left(\begin{array}{llll}
1 & 1 & 1 & 1 \\
1 & 1 & 1 & 1 \\
1 & 1 & 1 & 1 \\
1 & 1 & 1 & 1 \\
1 & 1 & 1 & 1
\end{array}\right)
$$

Berikutnya disajikan definisi $\left[a_{i j}\right]$ adalah submatriks soft dari $\left[b_{i j}\right]$, dinotasikan oleh $\left[a_{i j}\right] \widetilde{\subseteq}\left[b_{i j}\right],\left[a_{i j}\right]$ adalah proper submatriks soft dari $\left[b_{i j}\right]$, dinotasikan oleh $\left[a_{i j}\right] \widetilde{\subset}\left[b_{i j}\right]$ dan kesaman matriks soft dari $\left[a_{i j}\right]$ dan $\left[b_{i j}\right]$, dinotasikan oleh $\left[a_{i j}\right]=\left[b_{i j}\right]$. 
Definisi 2.4. Diberikan matriks $\left[a_{i j}\right],\left[b_{i j}\right] \in \mathbb{M}_{\mathbb{S}_{m \times n}}$.

i) Jika $a_{i j} \leq b_{i j}$ untuk setiap $i$ dan $j$, maka $\left[a_{i j}\right] \widetilde{\subseteq}\left[b_{i j}\right]$.

ii) Jika $a_{i j} \leq b_{i j}$ untuk setiap $i$ dan $j$, terdapat $a_{i j}<b_{i j}$, maka $\left[a_{i j}\right] \widetilde{\subset}\left[b_{i j}\right]$.

iii) Jika $a_{i j}=b_{i j}$ untuk setiap $i$ dan $j$, maka $\left[a_{i j}\right]=\left[b_{i j}\right]$.

Pada teori himpunan dikenal adanya operasi gabungan $U$, irisan $\cap$ dan konplemen, sedangkan pada logika matematika ada disjungsi $\vee$, konjungsi $\wedge$ dan negasi. Dari kondisi yang dimiliki himpunan dan logika matematika tersebut, diinduksi suatu definisi pada matriks soft, yaitu: operasi gabungan, operasi irisan dan operasi komplemen, yang berturut-turut dinotasikan oleh $\widetilde{U}, \widetilde{\cap}$ dan $[\ldots]^{C}$.

Definisi 2.5. Diberikan matriks $\left[a_{i j}\right],\left[b_{i j}\right] \in \mathbb{M}_{\mathbb{S}_{m \times n}}$. Untuk setiap $i$ dan $j$, didefinisikan:

i) $\left[a_{i j}\right] \widetilde{\cup}\left[b_{i j}\right] \stackrel{\text { def }}{=}\left[a_{i j} \vee b_{i j}\right]$.

ii) $\left[a_{i j}\right] \widetilde{\cap}\left[b_{i j}\right] \stackrel{\text { def }}{=}\left[a_{i j} \wedge b_{i j}\right]$.

iii) $\left[a_{i j}\right]^{C} \stackrel{\text { def }}{=}\left[1-a_{i j}\right]$.

\section{HASIL DAN PEMBAHASAN}

Lipschutz (1998) dan Michael (2016) menyatakan bahwa bahwa sifat involusi, sifat idempoten, sifat identitas, sifat konplemen, sifat komutatif, sifat asosiatif, sifat De Morgan, sifat distributif dan sifat absorpsi (penyerapan) adalah sifat-sifat yang khas pada teori himpunan. Dari sifat-sifat khas ini, dijadikan dasar untuk mengkontruksi sifat-sifat pada matriks soft, dengan cara menginduksi sifat khas tersebut yang dipadukan dengan konsep logika matematika.

Berikut disajikan sifat-sifat yang dinduksi dari sifat khas yang dimiliki oleh teori himpunan, diawali dengan sifat involusi.

Sifat involusi adalah salah satu sifat yang dimiliki oleh suatu himpunan $A$ dalam semesta $U$, yaitu: $\left(A^{C}\right)^{C}=A$. Kondisi ini, yang mendasari munculnya sifat involusi pada matriks soft, seperti disajikan pada proposisi berikut ini.

Proposisi 3.1. Jika $\left[a_{i j}\right] \in \mathbb{M}_{\mathbb{S}_{m \times n}}$, maka $\left(\left[a_{i j}\right]^{C}\right)^{C}=\left[a_{i j}\right]$.

\section{Bukti:}

Diambil sebarang $\left[a_{i j}\right] \in \mathbb{M}_{\mathbb{S}_{m \times n}}$. Berdasarkan Definisi 2.8 bagian (iii), untuk setiap $i$ dan $j$, diperoleh:

$$
\left(\left[a_{i j}\right]^{C}\right)^{C}=\left[1-a_{i j}\right]^{C}=\left[1-\left(1-a_{i j}\right)\right]=\left[a_{i j}\right]
$$

Suatu himpunan sebarang merupakan himpunan bagian bagi dirinya sendiri, dan himpunan kosong adalah himpunan bagian dari setiap himpunan. Dari fakta sifat himpunan ini, memunculkan suatu pertanyaan. Apakah sifat ini bisa berlaku pada matriks soft atau tidak? Dari pertanyaan ini, memunculkan sifat dari matriks soft yang analog dengan sifat himpunan tersebut, seperti yang disajikan pada proposisi berikut ini. 
Proposisi 3.2. Jika $\left[a_{i j}\right] \in \mathbb{M}_{\mathbb{S}_{m \times n}}$, maka $\left[a_{i j}\right] \widetilde{\subseteq}\left[a_{i j}\right]$ dan $[0] \widetilde{\subseteq}\left[a_{i j}\right]$.

Bukti:

Diambil sebarang $\left[a_{i j}\right] \in \mathbb{M}_{\mathbb{S}_{m \times n}}$. Karena $a_{i j} \in\{0,1\}$, untuk setiap $i$ dan $j$ selalu dipenuhi kondisi:

$$
a_{i j} \leq a_{i j} \text { dan } 0 \leq a_{i j}
$$

Oleh Karena itu, berdasarkan Definisi 2.4, diperoleh:

$$
\left[a_{i j}\right] \widetilde{\simeq}\left[a_{i j}\right] \text { dan }[0] \widetilde{\subseteq}\left[a_{i j}\right] \text {. }
$$

Berdasarkan hasil analisa proposisi 3.2, sifat yang diditanyakan kebenarannya di atas, dipenuhi oleh matriks soft, dengan kondisi matriks soft nol [0] analog dengan himpunan kosong $\varnothing$ pada teori himpunan.

Berikutnya disajikan sifat yang menghubungkan antara matriks soft nol [0], matriks soft $\left[a_{i j}\right]$ dan matriks soft semesta [1] pada $\mathbb{M}_{\mathbb{S}_{m \times n}}$.

Proposisi 3.3. Jika $\left[a_{i j}\right] \in \mathbb{M}_{\mathbb{S}_{m \times n}}$, maka $[0] \widetilde{\subseteq}\left[a_{i j}\right] \widetilde{\subseteq}[1]$.

\section{Bukti:}

Diambil sebarang $\left[a_{i j}\right] \in \mathbb{M}_{\mathbb{S}_{m \times n}}$. Mengingat $a_{i j} \in\{0,1\}$ untuk setiap $i$ dan $j$, dipenuhi kondisi:

$$
0 \leq a_{i j} \leq 1
$$

Akibatnya, berdasarkan Definisi 2.4 , diperoleh:

$$
[0] \widetilde{\simeq}\left[a_{i j}\right] \widetilde{\subseteq}[1]
$$

Relasi subset $\subseteq$ pada teori himpunan bersifat transitif, yaitu:

$$
\text { jika } A \subseteq B \text { dan } B \subseteq C \text {, maka } A \subseteq C \text {. }
$$

Kondisi ini, memunculkan pertanyaan berikutnya, apakah relasi subset $\widetilde{\subseteq}$ pada matriks soft juga berlaku sifat transitif atau tidak? Untuk menjawab pertanyaan tersebut, disajikan proposisi berikut ini.

Proposisi 3.4. Diberikan $\left[a_{i j}\right],\left[b_{i j}\right] \in \mathbb{M}_{\mathbb{S}_{m \times n}}$. Jika $\left[a_{i j}\right] \widetilde{\subseteq}\left[b_{i j}\right]$ dan $\left[b_{i j}\right] \widetilde{\subseteq}\left[c_{i j}\right]$, maka

$$
\left[a_{i j}\right] \widetilde{\subseteq}\left[c_{i j}\right] \text {. }
$$

Bukti:

Diambil sebarang $\left[a_{i j}\right],\left[b_{i j}\right] \in \mathbb{M}_{\mathbb{S}_{m \times n}}$. Misalkan untuk setiap $i$ dan $j$, dipenuhi kondisi:

$$
\left[a_{i j}\right] \widetilde{\simeq}\left[b_{i j}\right] \text { dan }\left[b_{i j}\right] \widetilde{\subseteq}\left[c_{i j}\right] \text {. }
$$

Oleh karena itu, berdasarkan Definisi 2.7, untuk setiap $i$ dan $j$, dipenuhi kondisi:

$$
a_{i j} \leq b_{i j} \text { dan } b_{i j} \leq c_{i j} \text {. }
$$

Karena relasi $\leq$ bersifat transitif pada himpunan bilangan real $\mathbb{R}$, yang mengakibatkan dipenuhi kondisi:

$$
a_{i j} \leq c_{i j}
$$


Akibatnya, berdasarkan Definisi 2.4, diperoleh:

$$
\left[a_{i j}\right] \widetilde{\subseteq}\left[c_{i j}\right]
$$

Analog dengan Proposisi 3.4, berikut disajikan kesamaan dua matriks soft pada $\mathbb{M}_{\mathbb{S}_{m \times n}}$.

Proposisi 3.5. Jika $\left[a_{i j}\right],\left[b_{i j}\right],\left[c_{i j}\right] \in \mathbb{M}_{\mathbb{S}_{m \times n}}$, maka $\left[a_{i j}\right]=\left[b_{i j}\right]$ dan $\left[b_{i j}\right]=\left[c_{i j}\right] j i k a$ dan

Bukti: hanya jika $\left[a_{i j}\right]=\left[c_{i j}\right]$.

Diambil sebarang $\left[a_{i j}\right],\left[b_{i j}\right] \in \mathbb{M}_{\mathbb{S}_{m \times n}}$. Misalkan untuk setiap $i$ dan $j$, dipenuhi kondisi:

$$
\left[a_{i j}\right]=\left[b_{i j}\right] \operatorname{dan}\left[b_{i j}\right]=\left[c_{i j}\right] .
$$

Berdasarkan Definisi 2.4, untuk setiap $i$ dan $j$, dipenuhi kondisi:

$$
a_{i j}=b_{i j} \text { dan } b_{i j}=c_{i j} \text {. }
$$

Karena relasi $=$ bersifat transitif pada himpunan bilangan real $\mathbb{R}$, yang mengakibatkan dipenuhi kondisi:

$$
a_{i j}=c_{i j}
$$

Oleh karena itu, berdasarkan Definisi 2.4, diperoleh:

$$
\left[a_{i j}\right]=\left[c_{i j}\right] .
$$

Sebaliknya, untuk setiap $\left[a_{i j}\right],\left[b_{i j}\right] \in \mathbb{M}_{\mathbb{S}_{m \times n}}$ dengan $\left[a_{i j}\right]=\left[c_{i j}\right]$, maka $a_{i j}=c_{i j}$, untuk setiap $i$ dan $j$.

Selanjutnya, relasi $=$ bersifat transitif pada himpunan bilangan real $\mathbb{R}$, yang mengakibatkan terdapat bilangan real $b_{i j}$ sedemikian sehingga

Akibatnya, berdasarkan Definsi 2.4 , dipenuhi kondisi:

$$
a_{i j}=b_{i j} \text { dan } b_{i j}=c_{i j} \text {. }
$$

$$
\left[a_{i j}\right]=\left[b_{i j}\right] \operatorname{dan}\left[b_{i j}\right]=\left[c_{i j}\right] \text {. }
$$

Analog dengan Proposisi 3.4, berikut disajikan kesamaan dua matriks soft pada $\mathbb{M}_{\mathbb{S}_{m \times n}}$.

Proposisi 3.6. Jika $\left[a_{i j}\right],\left[b_{i j}\right],\left[c_{i j}\right] \in \mathbb{M}_{\mathbb{S}_{m \times n}}$, maka $\left[a_{i j}\right] \widetilde{\subseteq}\left[b_{i j}\right]$ dan $\left[b_{i j}\right] \widetilde{\subseteq}\left[a_{i j}\right] j i k a$ dan hanya jika $\left[a_{i j}\right]=\left[b_{i j}\right]$.

\section{Bukti:}

Diambil sebarang $\left[a_{i j}\right],\left[b_{i j}\right] \in \mathbb{M}_{\mathbb{S}_{m \times n}}$ dengan $\left[a_{i j}\right] \widetilde{\simeq}\left[b_{i j}\right]$ dan $\left[b_{i j}\right] \widetilde{\subseteq}\left[a_{i j}\right]$ untuk setiap $i$ dan $j$. Berdasarkan Definisi 2.4, dipenuhi kondisi:

$$
a_{i j} \leq b_{i j} \text { dan } b_{i j} \leq a_{i j} \text {. }
$$

Oleh karena itu, berdasarkan kesamaan pada himpunan bilangan real $\mathbb{R}$, diperoleh:

Akibatnya,

$$
a_{i j}=b_{i j} \text {. }
$$

$$
\left[a_{i j}\right]=\left[b_{i j}\right]
$$


Sebaliknya, untuk setiap $\left[a_{i j}\right],\left[b_{i j}\right] \in \mathbb{M}_{\mathbb{S}_{m \times n}}$ dengan $\left[a_{i j}\right]=\left[b_{i j}\right]$, maka $a_{i j}=b_{i j}$, untuk setiap $i$ dan $j$. Akibatnya, berdasarkan sifat kesamaan pada bilangan real dipenuhi kondisi:

$$
a_{i j} \leq b_{i j} \text { dan } b_{i j} \leq a_{i j}
$$

Oleh karena itu, berdasarkan Definsi 2.4, dipenuhi kondisi:

$$
\left[a_{i j}\right] \widetilde{\subseteq}\left[b_{i j}\right] \text { dan }\left[b_{i j}\right] \widetilde{\subseteq}\left[a_{i j}\right] \text {. }
$$

Sifat idempoten adalah salah satu sifat yang dimiliki suatu himpunan $A$, yang dikaitkan dengan operasi gabungan dan irisan, yaitu:

$$
A \cup A=A \operatorname{dan} A \cap A=A .
$$

Dari sifat ini, diinduksi sifat yang lain dari matriks soft, seperti yang disajikan pada proposisi berikut ini.

Proposisi 3.7. Jika $\left[a_{i j}\right] \in \mathbb{M}_{\mathbb{S}_{m \times n}}$, maka $\left[a_{i j}\right] \widetilde{U}\left[a_{i j}\right]=\left[a_{i j}\right]$ dan $\left[a_{i j}\right] \widetilde{\cap}\left[a_{i j}\right]=\left[a_{i j}\right]$.

\section{Bukti:}

Diambil sebarang $\left[a_{i j}\right] \in \mathbb{M}_{\mathbb{S}_{m \times n}}$. Berdasarkan Definisi 2.5, untuk setiap $i$ dan $j$, diperoleh:

dan

$$
\left[a_{i j}\right] \widetilde{\cup}\left[a_{i j}\right]=\left[a_{i j} \vee a_{i j}\right]=\left[a_{i j}\right]
$$

$$
\left[a_{i j}\right] \widetilde{\cap}\left[a_{i j}\right]=\left[a_{i j} \wedge a_{i j}\right]=\left[a_{i j}\right]
$$

Himpunan $A$ dalam semesta $U$, mempunyai sifat identitas, yaitu: $A \bigcup \emptyset=A$ dengan identitas $\emptyset, A \cup U=U$ dengan identitas $A, A \cap U=A$ dengan identitas $U$, dan $A \cap \emptyset=\emptyset$ dengan identitas $A$. Berdasarkan kondisi ini, dikontruksi sifat yang lain dari matriks soft, seperti disajikan pada proposisi berikut ini.

Proposisi 3.8. Jika $\left[a_{i j}\right] \in \mathbb{M}_{\mathbb{S}_{m \times n}}$, maka

i) $\left[a_{i j}\right] \tilde{\mathrm{U}}[0]=\left[a_{i j}\right]$,

ii) $\left[a_{i j}\right] \widetilde{U}[1]=[1]$,

iii) $\left[a_{i j}\right] \widetilde{\cap}[1]=\left[a_{i j}\right]$, dan

iv) $\quad\left[a_{i j}\right] \widetilde{\cap}[0]=[0]$

\section{Bukti:}

Diambil sebarang $\left[a_{i j}\right] \in \mathbb{M}_{\mathbb{S}_{m \times n}}$. Berdasarkan Definisi 2.5, untuk setiap $i$ dan $j$, diperoleh:

i) $\left[a_{i j}\right] \widetilde{\cup}[0]=\left[a_{i j} \vee 0\right]=\left[a_{i j}\right]$,

ii) $\left[a_{i j}\right] \widetilde{U}[1]=\left[a_{i j} \vee 1\right]=[1]$,

iii) $\left[a_{i j}\right] \widetilde{\cap}[1]=\left[a_{i j} \wedge 1\right]=\left[a_{i j}\right]$, dan

iv) $\quad\left[a_{i j}\right] \widetilde{\cap}[0]=\left[a_{i j} \wedge 0\right]=[0]$. 
Sifat konplemen merupakan salah satu sifat yang terpat pada teori himpunan. Dari sifat ini, dapat diturunkan sifat yang lain dari matriks soft, yaitu:

Proposisi 3.9. Jika $\left[a_{i j}\right] \in \mathbb{M}_{\mathbb{S}_{m \times n}}$ maka

i) $\left[a_{i j}\right] \widetilde{\mathrm{U}}\left[a_{i j}\right]^{C}=[1]$

ii) $[1]^{C}=[0]$

iii) $\left[a_{i j}\right] \widetilde{\cap}\left[a_{i j}\right]^{C}=[0]$

iv) $[0]^{C}=[1]$

Bukti:

Diambil sebarang $\left[a_{i j}\right] \in \mathbb{M}_{\mathbb{S}_{m \times n}}$. Menggunakan kondisi Definisi 2.5, untuk setiap $i$ dan $j$, diperoleh:

i) $\left[a_{i j}\right] \widetilde{U}\left[a_{i j}\right]^{C}=\left[a_{i j} \vee\left(1-a_{i j}\right)\right]=[1]$

ii) $[1]^{C}=[1-1]=[0]$

iii) $\left[a_{i j}\right] \widetilde{\cap}\left[a_{i j}\right]^{C}=\left[a_{i j} \wedge\left(1-a_{i j}\right)\right]=[0]$

iv) $[0]^{C}=[1-0]=[1]$.

Sifat komutatif merupkan sifat banyak kita kenal pada operasi penjumlahan dan perkalian pada himpunan bilangan real. Sifat ini juga, dimiliki oleh teori himpunan pada operasi gabungan dan irisan, sehingga dari sifat ini, diturunkan sifat dari matriks soft set yang analog dengan sifat komutatif pada teori himpunan.

Proposisi 3.10 Jika $\left[a_{i j}\right],\left[b_{i j}\right] \in \mathbb{M}_{\mathbb{S}_{m \times n}}$ maka

i) $\quad\left[a_{i j}\right] \widetilde{\mathrm{U}}\left[b_{i j}\right]=\left[b_{i j}\right] \widetilde{\mathrm{U}}\left[a_{i j}\right]$.

ii) $\quad\left[a_{i j}\right] \widetilde{\cap}\left[b_{i j}\right]=\left[b_{i j}\right] \widetilde{\cap}\left[a_{i j}\right]$.

\section{Bukti:}

Diambil sebarang $\left[a_{i j}\right] \in \mathbb{M}_{\mathbb{S}_{m \times n}}$. Dengan menggunakan kondisi Definisi 2.8, untuk setiap $i$ dan $j$, diperoleh:

i) $\left[a_{i j}\right] \widetilde{\cup}\left[b_{i j}\right]=\left[a_{i j} \vee b_{i j}\right]=\left[b_{i j} \vee a_{i j}\right]=\left[b_{i j}\right] \widetilde{\cup}\left[a_{i j}\right]$.

ii) $\left[a_{i j}\right] \widetilde{\cap}\left[b_{i j}\right]=\left[a_{i j} \wedge b_{i j}\right]=\left[b_{i j} \wedge a_{i j}\right]=\left[b_{i j}\right] \widetilde{\cap}\left[a_{i j}\right]$.

Sifat asosiatif pada teori himpunan melibatkan operasi irisan atau gabungan dan tiga himpunan, yaitu: untuk sebarang himpunan $A, B$ dan $C$ dalam semesta $U$, berlaku:

$$
(A \cup B) \cup C=A \cup(B \cup C) \text { dan }(A \cap B) \cap C=A \cap(B \cap C) .
$$

Dari sifat ini, dinduksi sifat lain dari matriks soft, seperti disajikan pada Proposisi 3.11. 
Proposisi 3.11. Jika $\left[a_{i j}\right],\left[b_{i j}\right],\left[c_{i j}\right] \in \mathbb{M}_{\mathbb{S}_{m \times n}}$ maka

i) $\left(\left[a_{i j}\right] \widetilde{\cup}\left[b_{i j}\right]\right) \widetilde{U}\left[c_{i j}\right]=\left[a_{i j}\right] \widetilde{\cup}\left(\left[b_{i j}\right] \widetilde{\cup}\left[c_{i j}\right]\right)$.

ii) $\quad\left(\left[a_{i j}\right] \widetilde{\cap}\left[b_{i j}\right]\right) \widetilde{\cap}\left[c_{i j}\right]=\left[a_{i j}\right] \widetilde{\cap}\left(\left[b_{i j}\right] \widetilde{\cap}\left[c_{i j}\right]\right)$.

\section{Bukti:}

Diambil sebarang $\left[a_{i j}\right],\left[b_{i j}\right],\left[c_{i j}\right] \in \mathbb{M}_{\mathbb{S}_{m \times n}}$. Berdasarkan Definisi 2.5 , untuk setiap $i$ dan $j$, diperoleh:

i) $\left(\left[a_{i j}\right] \widetilde{\cup}\left[b_{i j}\right]\right) \widetilde{U}\left[c_{i j}\right]$

$$
\text { i) } \begin{aligned}
\left(\left[a_{i j}\right] \widetilde{\cup}\left[b_{i j}\right]\right) \widetilde{\cup}\left[c_{i j}\right] & =\left[\left(a_{i j} \vee b_{i j}\right) \vee c_{i j}\right] \\
& =\left[a_{i j} \vee\left(b_{i j} \vee c_{i j}\right)\right] \\
& =\left[a_{i j}\right] \widetilde{\cup}\left(\left[b_{i j}\right] \widetilde{\cup}\left[c_{i j}\right]\right) . \\
\text { ii) } \quad\left(\left[a_{i j}\right] \widetilde{\cap}\left[b_{i j}\right]\right) \widetilde{\cap}\left[c_{i j}\right] & =\left[\left(a_{i j} \wedge b_{i j}\right) \wedge c_{i j}\right] \\
& =\left[a_{i j} \wedge\left(b_{i j} \wedge c_{i j}\right)\right] \\
& =\left[a_{i j}\right] \widetilde{\cup}\left(\left[b_{i j}\right] \widetilde{\cup}\left[c_{i j}\right]\right) .
\end{aligned}
$$

Sifat De Morgan adalah salah satu sifat yang terkenal pada teori himpunan, dari sifat dapat diinduksi sifat lain, diantaranya pada logika matemtika. Berdasarkan fakta ini, dinduksi sifat De Morgan pada matriks soft, yang kebenarannya akan dibuktikan pada Proposisi 3.12.

Proposisi 3.12. Jika $\left[a_{i j}\right]$, $\left[b_{i j}\right] \in \mathbb{M}_{\mathbb{S}_{m \times n}}$ maka

i) $\left(\left[a_{i j}\right] \widetilde{\cup}\left[b_{i j}\right]\right)^{C}=\left[a_{i j}\right]^{C} \widetilde{\cap}\left[b_{i j}\right]^{C}$.

ii) $\left(\left[a_{i j}\right] \widetilde{\cap}\left[b_{i j}\right]\right)^{C}=\left[a_{i j}\right]^{C} \widetilde{\cup}\left[b_{i j}\right]^{C}$.

\section{Bukti:}

i) Diambil sebarang $\left[a_{i j}\right],\left[b_{i j}\right] \in \mathbb{M}_{\mathbb{S}_{m \times n}}$. Berdasarkan Definisi 2.5, untuk setiap $i$ dan $j$, diperoleh:

$$
\begin{aligned}
\left(\left[a_{i j}\right] \widetilde{\cup}\left[b_{i j}\right]\right)^{C} & =\left[a_{i j} \vee b_{i j}\right]^{C} \\
& =\left[1-\left(a_{i j} \vee b_{i j}\right)\right] \\
& =\left[\left(1-a_{i j}\right) \wedge\left(1-b_{i j}\right)\right] \\
& =\left[a_{i j}\right]^{C} \widetilde{\cap}\left[b_{i j}\right]^{C} .
\end{aligned}
$$

ii) Diambil sebarang $\left[a_{i j}\right],\left[b_{i j}\right] \in \mathbb{M}_{\mathbb{S}_{m \times n}}$. Berdasarkan Definisi 2.5, untuk setiap $i$ dan $j$, diperoleh:

$$
\begin{aligned}
\left(\left[a_{i j}\right] \widetilde{\cap}\left[b_{i j}\right]\right)^{C} & =\left[a_{i j} \wedge b_{i j}\right]^{C} \\
& =\left[1-\left(a_{i j} \wedge b_{i j}\right)\right] \\
& =\left[\left(1-a_{i j}\right) \vee\left(1-b_{i j}\right)\right] \\
& =\left[a_{i j}\right]^{C} \widetilde{\cup}\left[b_{i j}\right]^{C} .
\end{aligned}
$$


Berdasarkan hasil analisa pembuktian di atas, sifat De Morgan berlaku pada matriks soft. Berikut diberikan contoh, sebagai ilustrasi dari sifat De Morgan pada Proposisi 3.12.

Contoh 3.1. Jika $\left[a_{i j}\right],\left[b_{i j}\right] \in \mathbb{M}_{S_{5 \times 4}}$, dengan

maka

$$
\left[a_{i j}\right]=\left(\begin{array}{cccc}
0 & 1 & 0 & 0 \\
0 & 0 & 1 & 0 \\
0 & 1 & 0 & 0 \\
0 & 0 & 1 & 0 \\
0 & 1 & 0 & 0
\end{array}\right) \operatorname{dan}\left[b_{i j}\right]=\left(\begin{array}{cccc}
1 & 0 & 1 & 0 \\
1 & 0 & 0 & 0 \\
1 & 0 & 1 & 0 \\
1 & 0 & 0 & 1 \\
1 & 0 & 1 & 0
\end{array}\right),
$$

$$
\begin{aligned}
\left(\left[a_{i j}\right] \widetilde{\cup}\left[b_{i j}\right]\right)^{C} & =\left\{\left(\begin{array}{llll}
0 & 1 & 0 & 0 \\
0 & 0 & 1 & 0 \\
0 & 1 & 0 & 0 \\
0 & 0 & 1 & 0 \\
0 & 1 & 0 & 0
\end{array}\right) \widetilde{U}\left(\begin{array}{llll}
1 & 0 & 1 & 0 \\
1 & 0 & 0 & 0 \\
1 & 0 & 1 & 0 \\
1 & 0 & 0 & 1 \\
1 & 0 & 1 & 0
\end{array}\right)\right\}^{C} \\
& =\left(\begin{array}{llll}
1 & 1 & 1 & 0 \\
1 & 0 & 1 & 0 \\
1 & 1 & 1 & 0 \\
1 & 0 & 1 & 1 \\
1 & 1 & 1 & 0
\end{array}\right) \\
& =\left(\begin{array}{llll}
0 & 0 & 0 & 1 \\
0 & 1 & 0 & 1 \\
0 & 0 & 0 & 1 \\
0 & 1 & 0 & 0 \\
0 & 0 & 0 & 1
\end{array}\right)
\end{aligned}
$$

dan

$$
\begin{aligned}
{\left[a_{i j}\right]^{C} \widetilde{\cap}\left[b_{i j}\right]^{C} } & =\left(\begin{array}{llll}
0 & 1 & 0 & 0 \\
0 & 0 & 1 & 0 \\
0 & 1 & 0 & 0 \\
0 & 0 & 1 & 0 \\
0 & 1 & 0 & 0
\end{array}\right)^{C} \widetilde{\cap}\left(\begin{array}{llll}
1 & 0 & 1 & 0 \\
1 & 0 & 0 & 0 \\
1 & 0 & 1 & 0 \\
1 & 0 & 0 & 1 \\
1 & 0 & 1 & 0
\end{array}\right)^{C} \\
& =\left(\begin{array}{llll}
1 & 0 & 1 & 1 \\
1 & 1 & 0 & 1 \\
1 & 0 & 1 & 1 \\
1 & 1 & 0 & 1 \\
1 & 0 & 1 & 1
\end{array}\right) \widetilde{\cap}\left(\begin{array}{llll}
0 & 1 & 0 & 1 \\
0 & 1 & 1 & 1 \\
0 & 1 & 0 & 1 \\
0 & 1 & 1 & 0 \\
0 & 1 & 0 & 1
\end{array}\right) \\
& =\left(\begin{array}{llll}
0 & 0 & 0 & 1 \\
0 & 1 & 0 & 1 \\
0 & 0 & 0 & 1 \\
0 & 1 & 0 & 0 \\
0 & 0 & 0 & 1
\end{array}\right) .
\end{aligned}
$$


Jadi, $\left(\left[a_{i j}\right] \widetilde{\cup}\left[b_{i j}\right]\right)^{C}=\left[a_{i j}\right]^{C} \widetilde{\cap}\left[b_{i j}\right]^{C}$.

Selanjutnya,

$$
\begin{aligned}
\left(\left[a_{i j}\right] \widetilde{\cap}\left[b_{i j}\right]\right)^{C} & =\left\{\left(\begin{array}{llll}
0 & 1 & 0 & 0 \\
0 & 0 & 1 & 0 \\
0 & 1 & 0 & 0 \\
0 & 0 & 1 & 0 \\
0 & 1 & 0 & 0
\end{array}\right) \widetilde{\cap}\left(\begin{array}{llll}
1 & 0 & 1 & 0 \\
1 & 0 & 0 & 0 \\
1 & 0 & 1 & 0 \\
1 & 0 & 0 & 1 \\
1 & 0 & 1 & 0
\end{array}\right)\right\}^{C} \\
& =\left(\begin{array}{llll}
0 & 0 & 0 & 0 \\
0 & 0 & 0 & 0 \\
0 & 0 & 0 & 0 \\
0 & 0 & 0 & 0 \\
0 & 0 & 0 & 0
\end{array}\right) \\
& =\left(\begin{array}{llll}
1 & 1 & 1 & 1 \\
1 & 1 & 1 & 1 \\
1 & 1 & 1 & 1 \\
1 & 1 & 1 & 1 \\
1 & 1 & 1 & 1
\end{array}\right) \\
& =[1],
\end{aligned}
$$

dan

$$
\begin{aligned}
{\left[a_{i j}\right]^{C} \widetilde{U}\left[b_{i j}\right]^{C} } & =\left(\begin{array}{llll}
0 & 1 & 0 & 0 \\
0 & 0 & 1 & 0 \\
0 & 1 & 0 & 0 \\
0 & 0 & 1 & 0 \\
0 & 1 & 0 & 0
\end{array}\right)^{C} \widetilde{U}\left(\begin{array}{llll}
1 & 0 & 1 & 0 \\
1 & 0 & 0 & 0 \\
1 & 0 & 1 & 0 \\
1 & 0 & 0 & 1 \\
1 & 0 & 1 & 0
\end{array}\right)^{C} \\
& =\left(\begin{array}{llll}
1 & 0 & 1 & 1 \\
1 & 1 & 0 & 1 \\
1 & 0 & 1 & 1 \\
1 & 1 & 0 & 1 \\
1 & 0 & 1 & 1
\end{array}\right) \widetilde{U}\left(\begin{array}{llll}
0 & 1 & 0 & 1 \\
0 & 1 & 1 & 1 \\
0 & 1 & 0 & 1 \\
0 & 1 & 1 & 0 \\
0 & 1 & 0 & 1
\end{array}\right) \\
& =\left(\begin{array}{llll}
1 & 1 & 1 & 1 \\
1 & 1 & 1 & 1 \\
1 & 1 & 1 & 1 \\
1 & 1 & 1 & 1 \\
1 & 1 & 1 & 1
\end{array}\right) \\
& =\left[\begin{array}{lll}
1] &
\end{array}\right.
\end{aligned}
$$

Jadi, $\left(\left[a_{i j}\right] \widetilde{\cap}\left[b_{i j}\right]\right)^{C}=\left[a_{i j}\right]^{C} \widetilde{\cup}\left[b_{i j}\right]^{C}$. 
Sifat berikutnya yang dimiliki oleh teori himpunan adalah sifat distributif. Sifat ini, melibatkan dua operasi, yaitu: operasi irisan dan gabungan, dan melibatkan tiga himpunan, yaitu: untuk sebarang himpunan $A, B$ dan $C$ dalam semesta $U$, berlaku:

$$
A \cup(B \cap C)=(A \cup B) \cap(A \cup C) \text { dan } A \cap(B \cup C)=(A \cap B) \cup(A \cap C)
$$

Dari sifat distributif ini, diturunkan sifat baru pada matriks soft, seperti disajikan pada proposisi berikut ini.

Proposisi 3.13. Jika $\left[a_{i j}\right],\left[b_{i j}\right],\left[c_{i j}\right] \in \mathbb{M}_{\mathbb{S}_{m \times n}}$ maka

i) $\quad\left[a_{i j}\right] \widetilde{\cup}\left(\left[b_{i j}\right] \widetilde{\cap}\left[c_{i j}\right]\right)=\left(\left[a_{i j}\right] \widetilde{\cup}\left[b_{i j}\right]\right) \widetilde{\cap}\left(\left[a_{i j}\right] \widetilde{\cup}\left[c_{i j}\right]\right)$.

ii) $\quad\left[a_{i j}\right] \widetilde{\cap}\left(\left[b_{i j}\right] \widetilde{U}\left[c_{i j}\right]\right)=\left(\left[a_{i j}\right] \widetilde{\cap}\left[b_{i j}\right]\right) \widetilde{U}\left(\left[a_{i j}\right] \widetilde{\cap}\left[c_{i j}\right]\right)$.

\section{Bukti:}

i) Diambil sebarang $\left[a_{i j}\right],\left[b_{i j}\right],\left[c_{i j}\right] \in \mathbb{M}_{\mathbb{S}_{m \times n}}$. Berdasarkan Definisi 2.8, untuk setiap $i$ dan $j$, diperoleh:

$$
\begin{aligned}
{\left[a_{i j}\right] \widetilde{\cup}\left(\left[b_{i j}\right] \widetilde{\cap}\left[c_{i j}\right]\right) } & =\left[a_{i j} \vee\left(b_{i j} \wedge c_{i j}\right)\right] \\
& =\left[\left(a_{i j} \vee b_{i j}\right) \wedge\left(a_{i j} \vee c_{i j}\right)\right] \\
& =\left[\left(a_{i j} \vee b_{i j}\right)\right] \widetilde{\cap}\left[\left(a_{i j} \vee c_{i j}\right)\right] \\
& =\left(\left[a_{i j}\right] \widetilde{\cup}\left[b_{i j}\right]\right) \widetilde{\cap}\left(\left[a_{i j}\right] \widetilde{\cup}\left[c_{i j}\right]\right)
\end{aligned}
$$

ii) Diambil sebarang $\left[a_{i j}\right],\left[b_{i j}\right],\left[c_{i j}\right] \in \mathbb{M}_{\mathbb{S}_{m \times n}}$. Berdasarkan Definisi 2.5, untuk setiap $i$ dan $j$ diperoleh:

$$
\begin{aligned}
{\left[a_{i j}\right] \widetilde{\cap}\left(\left[b_{i j}\right] \widetilde{U}\left[c_{i j}\right]\right) } & =\left[a_{i j} \wedge\left(b_{i j} \vee c_{i j}\right)\right] \\
& =\left[\left(a_{i j} \wedge b_{i j}\right) \vee\left(a_{i j} \wedge c_{i j}\right)\right] \\
& =\left[\left(a_{i j} \wedge b_{i j}\right)\right] \widetilde{U}\left[a_{i j} \wedge c_{i j}\right] \\
& =\left(\left[a_{i j}\right] \widetilde{\cap}\left[b_{i j}\right]\right) \widetilde{U}\left(\left[a_{i j}\right] \widetilde{\cap}\left[c_{i j}\right]\right)
\end{aligned}
$$

Berikut disajikan sifat absorpsi (penyerapan), yang diinduksi dari sifat absorpsi himpunan.

Proposisi 3.14. Jika $\left[a_{i j}\right]$, $\left[b_{i j}\right] \in \mathbb{M}_{\mathbb{S}_{m \times n}}$, maka

$$
\left[a_{i j}\right] \widetilde{\cup}\left(\left[a_{i j}\right] \widetilde{\cap}\left[b_{i j}\right]\right)=\left[a_{i j}\right] \text {, dan }\left[a_{i j}\right] \widetilde{\cap}\left(\left[a_{i j}\right] \widetilde{\cup}\left[b_{i j}\right]\right)=\left[a_{i j}\right] \text {. }
$$

Bukti:

Untuk membuktikan $\left[a_{i j}\right] \widetilde{\cup}\left(\left[a_{i j}\right] \widetilde{\cap}\left[b_{i j}\right]\right)=\left[a_{i j}\right]$, akan dibuktikan terlebih dahulu:

$$
\left[a_{i j}\right] \widetilde{\cap}\left[b_{i j}\right] \subseteq\left[a_{i j}\right]
$$

Karena $\left[a_{i j}\right] \widetilde{\cap}\left[b_{i j}\right]=a_{i j} \wedge b_{i j}$ untuk setiap $i$ dan $j$, maka

$$
a_{i j} \wedge b_{i j} \leq a_{i j}
$$


Oleh karena itu, berdasarkan Definisi 2.4, diperoleh:

$$
\left[a_{i j}\right] \widetilde{\cap}\left[b_{i j}\right] \subseteq\left[a_{i j}\right]
$$

Akibatnya, berdasarkan Proposisi 3.7, diperoleh:

$$
\left[a_{i j}\right] \widetilde{\cup}\left(\left[a_{i j}\right] \widetilde{\cap}\left[b_{i j}\right]\right)=\left[a_{i j}\right] \text {. }
$$

Selanjutnya, untuk membuktikan $\left[a_{i j}\right] \widetilde{\cap}\left(\left[a_{i j}\right] \widetilde{\cup}\left[b_{i j}\right]\right)=\left[a_{i j}\right]$, akan dibuktikan terlebih dahulu:

$$
\left[a_{i j}\right] \subseteq\left(\left[a_{i j}\right] \widetilde{\cup}\left[b_{i j}\right]\right)
$$

Karena, $\left(\left[a_{i j}\right] \widetilde{\cup}\left[b_{i j}\right]\right)=a_{i j} \vee b_{i j}$ untuk setiap $i$ dan $j$, maka untuk setiap $i$ dan $j$, berlaku:

$$
a_{i j} \leq a_{i j} \wedge b_{i j}
$$

Oleh karena itu, berdasarkan Definisi 2.4, diperoleh:

$$
\left[a_{i j}\right] \subseteq\left[a_{i j}\right] \widetilde{\cup}\left[b_{i j}\right]
$$

Akibatnya, berdasarkan Proposisi 3.7 dan Proposisi 3.8, diperoleh:

$$
\left[a_{i j}\right] \widetilde{\cap}\left(\left[a_{i j}\right] \widetilde{\cup}\left[b_{i j}\right]\right)=\left[a_{i j}\right] \text {. }
$$

\section{SIMPULAN}

Berdasarkan hasil analisa dari pembahasan, matriks soft memiliki sifat yang khas seperti yang dimiliki oleh teori himpunan, yaitu: Sifat involusi, sifat idempoten, sifat identitas, sifat konplemen, sifat komutatif, sifat asosiatif, hukum De Morgan, hukum distributif dan sifat absorpsi (penyerapan). Sifat-sifat dasar ini, harapan kedepannya dapat dijadikan dasar untuk penelitian matriks soft berikutnya.

\section{REFERENSI}

Abdurrahman, S. (2020). w - fuzzy subsemiring.pdf. Jurnal Matematika, Sains, dan Teknologi, 21(1), 1-10. https://doi.org/https://doi.org/10.33830/jmst.v21i1.673.2020.

Çağman, N. \& Enginoğlu, S. (2010). Soft matrix theory and its decision making. Computers and Mathematics with Applications, 59(10), 3308-3314. https://doi.org/10.1016/j.camwa.2010. 03.015.

Lipschutz, S. (1998). Set and Basic Operations on Sets. In Schaum's Outline of Theory and Problems of Set Theory (2nd ed, pp. 1-33). The McGraw-Hili Companies, Inc.

Maji, P. K., Biswas, R., \& Roy, A. R. (2003). Soft set theory. Journal Computers and Mathematics with Applications, 45(4-5), 555-562. https://doi.org/10.1016/S0898-1221(03)00016-6.

Michael, L. O. (2016). Set Theory. In A First Course In Mathematical Logic And Set Theory (pp. 117155). John Wiley \& Sons, Inc., Hoboken, New Jersey.

Molodtsov, D. (1999). Soft set theory first results. Journal Computers and Mathematics with Applications, 37, 19-31. https://www.sciencedirect.com/science/article/pii/ S0898122199000565.

Mondal, S., \& Pal, M. (2011). Soft matrices. African Journal of Mathematics and Computer Science Research, 7(13), 379-388. https://doi.org/https://doi.org/10.5897/AJMCSR.9000057. 
Rosenfeld, A. (1971). Fuzzy groups. Journal of Mathematical Analysis and Applications, 35(3), 512 517. https://doi.org/10.1016/0022-247X(71)90199-5.

Vijayabalaji, S., \& Ramesh, A. (2013). A new decision making theory in soft matrices. International Journal of Pure and Applied Mathematics, 86(6), 927-939. https://doi.org/http://dx.doi.org/ 10.12732/ijpam.v86i6.6.

Zadeh, L. A. (1965). Fuzzy Sets. Information and Control, 8(3), 338-353. https://doi.org/https://doi.org/10.1016/S0019-9958(65)90241-X.

Zhang, Z. (2014). A new method for decision making based on soft matrix theory. Journal of Scientific Research and Reports, 3(15), 2110-2117. https://doi.org/10.9734//srr/2014/10507. 